\title{
Ethnocultural and ethnodemographic features of the Mongols of China in the context of preserving the identity of non-Han peoples
}

\author{
Marina Voronina $^{1^{*}}$ \\ ${ }^{1}$ Far Eastern Federal University, 692524 Ussuriysk, Russia.
}

\begin{abstract}
The article analyzes ethno-demographic indicators of the non-Han Chinese people - the Mongols: the dynamics of their number, growth rates, gender and age structure, characteristics of their settlement, the share of the ethnic group in the population of administrative areas of China. The ethnoeconomic aspects of the Mongolian life of China were revealed: traditional activities and new industries based on the use of local mineral resources. The contribution of the Mongols to the sociocultural space of national suburbs, development of ethno-tourism and popularization of culture, customs and traditions were analyzed. The author uses information obtained during the field ethnographic research in the Duerbote-Mongolian Autonomous Region, Heilongjiang Province, China
\end{abstract}

\section{Introduction}

Modern China is a multinational state. The population can be divided into the Han people which accounts for $91.6 \%$ of the Chinese population, and the Non-han people. The latter category includes 55 ethnic groups with a total number of about 112 million people represented by six language families. The most numerous ones are the Thai people of Zhuang (16 926381 people), the small people Loba (3 682 people) living in the Tibet Autonomous Region. The ninth largest non-Han people is the Mongols of China.

The purpose of the study is to analyze ethnic and demographic features of the Mongols of China, features and areas of their settlement, ethnic and cultural characteristics, economic structure and traditional activities aimed at preserving ethnic identity. Special attention is paid to the development of ethno-tourism in the Duerbote-Mongolian Autonomous region (Heilongjiang Province, China).

\section{Materials and Methods}

The study is based on the analysis of statistical data published by the results of the All-China population censuses. To interpret ethno-demographic indicators, elements of a phased multi-criteria analysis were used. In order to study ethnocultural and ethno-economic features of the Mongols of China, the author conducted a two-year field ethnographic research in the Duerbot-Mongol Autonomous Region (Heilongiiang Province, China).

\section{Results}

The Mongols of China are one of the largest non-Han peoples. According to the last census of 2010, there are $5,981,840$ people. The 2000 census recorded 5,813,947 people. Thus, over the ten-year period, the growth of amounted to more than 160 thousand. For China, this indicates a slow growth. In 1964-1990, the number grew faster (Fig. 1) due to the fact that the non-Han population (including the Chinese Mongols) was not involved in the state policy of birth control. Non-interference in demographic processes was due to a small number of many peoples inhabiting the national outskirts and the urgent need to reproduce their labor resources. However, with the beginning of economic reforms, birth control measures began to spread to the non-Han population [1] which decreased the growth of the Mongolian population of China in the 1990s and 2000-2010s.

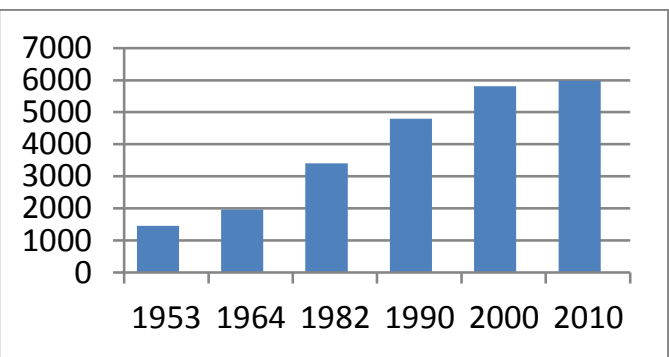

Fig. 1. Dynamics of the population of the Mongols of China, thousand people [2]

A decline in population growth rates and a decrease in the birth rate shifted the age and gender structure of the Mongolian population. Figure 2 shows that the share of children is relatively small (19.7\%). The share of 60 -year

\footnotetext{
* Corresponding author: voronina 2003@ mail.ru
} 
old and older exceeds $7.5 \%$. This increases the "demographic load" on the working-age population.

As for the gender structure, there are no clear imbalances. The share of men and women is identical (Fig. 2).

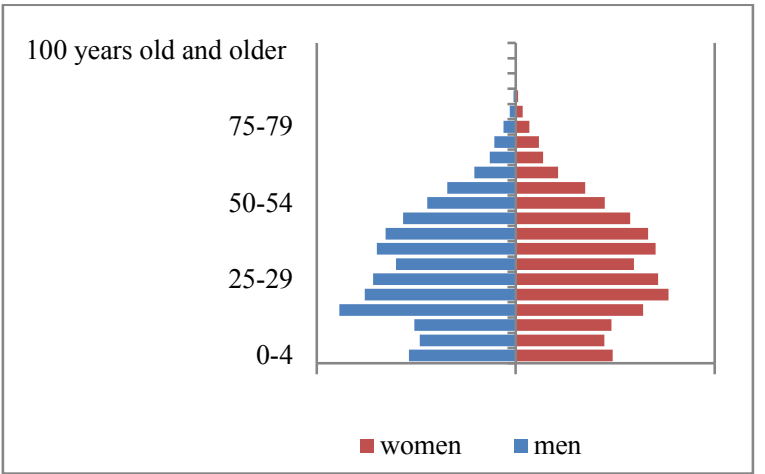

Fig. 2. Age and gender structure of the Mongols of China [2]

Table 1 shows quantitative and geographical features of the Mongol population. They live in the autonomous region (AR) of Inner Mongolia - 4,226,090 people more than $70 \%$ of all Mongols). Their communities live in Liaoning Province (11\%), Hebei Province (3\%), Xinjiang Uygur AR and Jilin Province (2.6\%), Heilongjiang Province $(2.1 \%)$. Thus, the main distribution areas of the Mongols are the north, northeast and northwest. The most unattractive place is steppes and semi-deserts - the highlands of Tibet. Only 307 people $(0.005 \%$ of the total number) live there.

Table 1. The number of Chinese Mongols in the provinces, autonomous regions and cities according to the data of the AllChinese census of 2010 [3]

\begin{tabular}{|l|l|l|l|c|c|}
\hline No & $\begin{array}{c}\text { Name of } \\
\text { provinces }\end{array}$ & Status & Part & $\begin{array}{c}\text { Number } \\
\text { of } \\
\text { people }\end{array}$ & $\begin{array}{c}\text { \% of the } \\
\text { total } \\
\text { Mongolian } \\
\text { population } \\
\text { of China }\end{array}$ \\
\hline 1 & $\begin{array}{l}\text { Internal } \\
\text { Mongolia }\end{array}$ & AR & North & $4,226,090$ & 70.6 \\
\hline 2 & Liaoning & Province & Northeast & 657869 & 11.0 \\
\hline 3 & Hebei & Province & North & 180849 & 3.0 \\
\hline 4 & $\begin{array}{l}\text { Xinjiang } \\
\text { Uygur }\end{array}$ & AR & Northwest & 156280 & 2.6 \\
\hline 5 & Jilin & Province & Northeast & 145039 & 2.6 \\
\hline 6 & Heilongjiang & Province & Northeast & 125483 & 2.1 \\
\hline 7 & Qinghai & Province & Southwest & 99,815 & 1.7 \\
\hline 8 & Beijing & UIC & North & 76,736 & 1.3 \\
\hline 9 & Henan & Province & North & 63473 & 1.1 \\
\hline 10 & Guizhou & Province & West & $41 \quad 561$ & 0.7 \\
\hline 11 & Sichuan & Province & West & 36,646 & 0.6 \\
\hline 12 & Yunnan & Province & West & 22,624 & 0.4 \\
\hline 13 & Tianjin & UIC & North & 20328 & 0.3 \\
\hline 14 & Shandong & Province & East & 17,669 & 0.3 \\
\hline 15 & Guangdong & Province & Southeast & 14331 & 0.2 \\
\hline
\end{tabular}

\begin{tabular}{|l|l|l|l|l|c|}
\hline 16 & Shanghai & UIC & East & 11,238 & 0.2 \\
\hline 17 & Gansu & Province & Northwest & 10,935 & 0.2 \\
\hline 18 & Jiangsu & Province & East & 10691 & 0.2 \\
\hline 19 & Hubei & Province & $\begin{array}{l}\text { Central } \\
\text { South }\end{array}$ & 10,318 & 0.2 \\
\hline 20 & Shaanxi & Province & Northwest 6,976 & 0.1 \\
\hline 21 & Zhejiang & Province & East & 6,872 & 0.1 \\
\hline 22 & Ningxia Hui & AR & Northwest & 6,661 & 0.1 \\
\hline 23 & Fujian & Province & $\begin{array}{l}\text { South - } \\
\text { East }\end{array}$ & 5,830 & 009 \\
\hline 24 & Chongqing & UIC & West & 5,688 & 009 \\
\hline 25 & Shanxi & Province & North & 5,070 & 0.08 \\
\hline 26 & Hunan & Province & $\begin{array}{l}\text { Centro- } \\
\text { South }\end{array}$ & 3,693 & 0.06 \\
\hline 27 & Jiangxi & Province & $\begin{array}{l}\text { Central } \\
\text { South }\end{array}$ & 3,479 & 0.06 \\
\hline 28 & Hainan & Province & Southeast & 3,463 & 0.06 \\
\hline 29 & $\begin{array}{l}\text { Guangxi } \\
\text { Zhuang }\end{array}$ & AR & Southeast & 3,017 & 0.05 \\
\hline 30 & Anhui & Province & East & 2,809 & 0.05 \\
\hline 31 & Tibet & AR & West & 307 & 0.005 \\
\hline $\mathbf{3 2}$ & Total & $\mathbf{5 9 8 1 ~ 8 4 0}$ & $\mathbf{1 0 0}$ \\
\hline
\end{tabular}

The data show the general picture of distribution of the Mongols. They live in vast areas (about $2 / 3$ of the territory) bordering the Great Chinese Plain - the main area of residence of the Han people. Secondly, several non-Han ethnic groups live within the same territories (Yunnan, Guizhou, Sichuan provinces are among the most multiethnic). Even ethnic autonomous regions are not homogeneous by nationality features. Finally, border districts have less productive lands (highland areas of Tibetan and Qinghai provinces, deserts and semi-deserts of Inner Mongolia, Xinjiang-Uygur Province and Gansu Province).

The Mongols have their own written and spoken language which belongs to the Mongolian group of the Altai linguistic family. There are several dialects. Mongolian writing was formed in the 13th century on the basis of the writing of the ancient Uighurs and Huns. At the same time, ethnic assimilation (Chinaization of the Mongolian population) has intensified. As a result, the native language is not spoken by the Mongolian youth. Good of the language of the Han ethnic group is a bonus when entering universities or searching for a job.

The main area where $f$ the Mongols of China live is Inner Mongolia with an administrative center in Hohhot. It was founded on May 1, 1947 and became the first autonomous region in China. Its size exceeds 1.18 million $\mathrm{km}^{2}$ (12\% of the total area of China). Inner Mongolia is second to Xinjiang Uygur.

Inner Mongolia is located in Northern China at 900$1300 \mathrm{~m}$ above the sea level. Within its borders, there are pastures (cattle breeding was a traditional occupation of the Mongols). Cattle, sheep, horses, camels are bred. Breeding wool cattle stimulated the development of the 
textile industry. Wool fabrics are produced from local raw materials.

Natural resources of the autonomous region are diverse. The region is rich in mineral resources. A number of industries process local raw materials (e.g., ferrous metallurgy). For the development of ferrous metallurgy, conditions are ideal: proximity of iron ore deposits and coal basins. Baotou is one of the leading metallurgical centers in China. It is also known for the unique deposit of rare-earth metals in Bayan-Obo [4]. The foothills of the Great Khingan on the eastern periphery of Inner Mongolia are a forest region with developed timber (mainly logging) and Hebraization industries.

All these industries are new to the area. The traditional economic structure of the local population is undergoing transformations.

The living standards of the Mongols are much lower than people living in the Han provinces. Differences exist despite the implementation of the national "Go to the West" policy designed to eliminate socio-economic contrasts in the development of the coastal and "continental" provinces.

Inner Mongolia is the largest but not the only autonomous Mongol formation in China. Their large communities live in a number of special zones that appeared after the formation of the People's Republic of China in 1949:

- Haishi-Mongolo-Tibet Autonomous Region (Qinghai province);

- Bayan-Gol-Mongol Autonomous Region (Xinjiang Uygur AR)

- Boro-Tala-Mongol Autonomous Region (Xinjiang Uygur AR)

- Zubey-Mongol Autonomous Region (Jiuquan, Gansu Province);

- Kharachin-Tsoi-Mongol Autonomous Region (Chaoyang, Liaoning Province);

- Fuxin-Mongol Autonomous Region (Fuxin, Liaoning Province);

- Qian-Gorlos-Mongol Autonomous Region (Songyuan, Jilin Province);

- Duerbote-Mongol Autonomous Region (Daqing, Heilongjiang Province) and others.

\section{Discussion}

For two years, the author conducted an ethnogeographical research in several regions. For a long time, Duerbote-Mongol Autonomous Region was part of Qiqihar. In 1992, it was transferred to Daqing city district. An analysis of ethno-demographic data showed that despite the fact that the region is called Mongolian, the Mongols make up only $18 \%$ of its population. However, this district is headed by Mongols.

Duerbote is one of the poorest areas of Heilongjiang Province. According to the observations, the Mongols have a very modest lifestyle. Their primitive dwellings are clay-covered houses lacking amenities. People and livestock share a common yard.

In addition to the traditional economic activities, they are engaged in ethno-tourism. Its development, is crucial in the areas inhabited by the Mongols. Ethno-tourism is one of the directions for preserving the sociocultural space of the national outskirts of China. Great attention is paid to the preservation of ethnocultural values and ethnic identity of the peoples. In Inner Mongolia, regostration of ethnocultural resources was completed [5]. This inventory of ethno-cultural values creates important prerequisites for the formation of a new tourism industry. An element of its infrastructure is an ethnographic facility created in the Duerbote-Mongol Autonomous Region (Fig. 3). There are several stylized yurts that serve as banquet halls. Exotic traditional Mongolian dishes are prepared and served based on medieval recipes.

In addition to excursions to the ethnographic facility, there are a lot of entertainment activities: archery, javelin throwing, horse riding, camel riding. The workers show traditional national costumes (Fig. 4), play music, play national instruments.

Visitors can get acquainted with customs of the Mongols, be involved in their daily activities. They can learn principle of operation of a vintage pump to extract water from underground wells (Fig. 5).

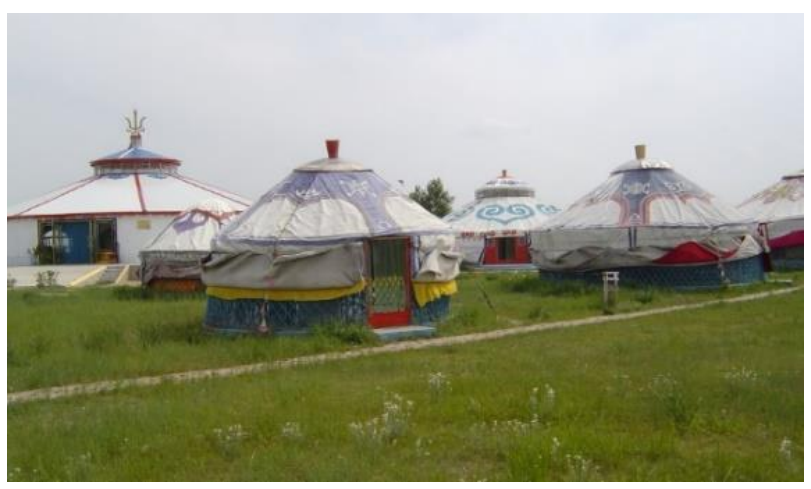

Fig. 3. Ethnographic facility in the Duerbote-Mongol Autonomous region, Heilongjiang Province, China (author's photo)

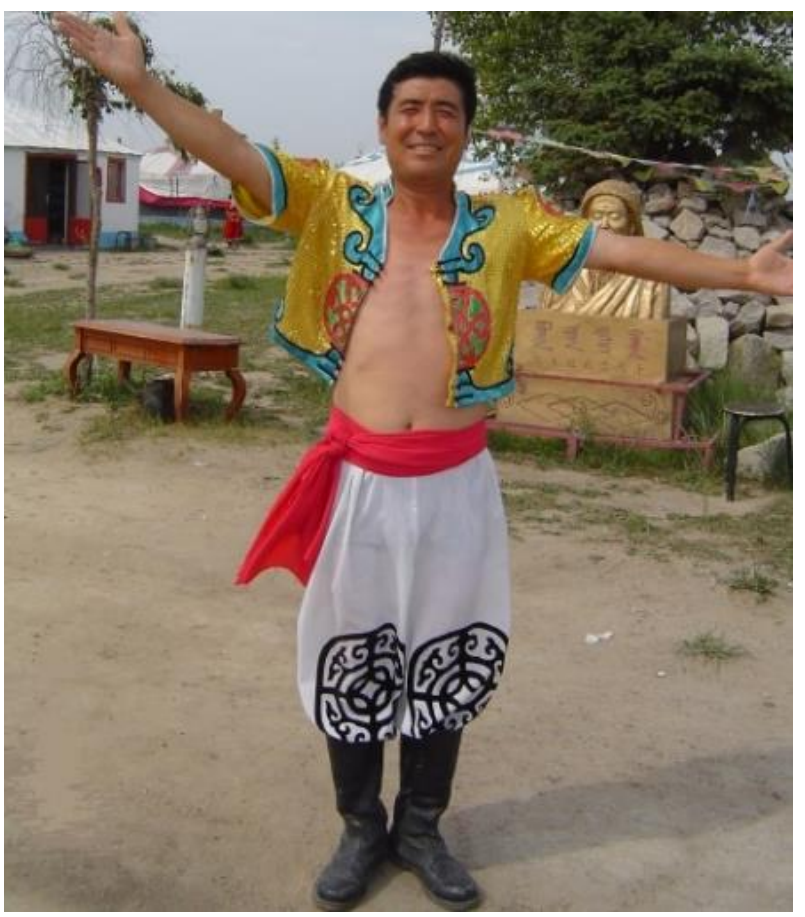

Fig. 4. The Mongolian of China in the traditional costume (author's photo) 


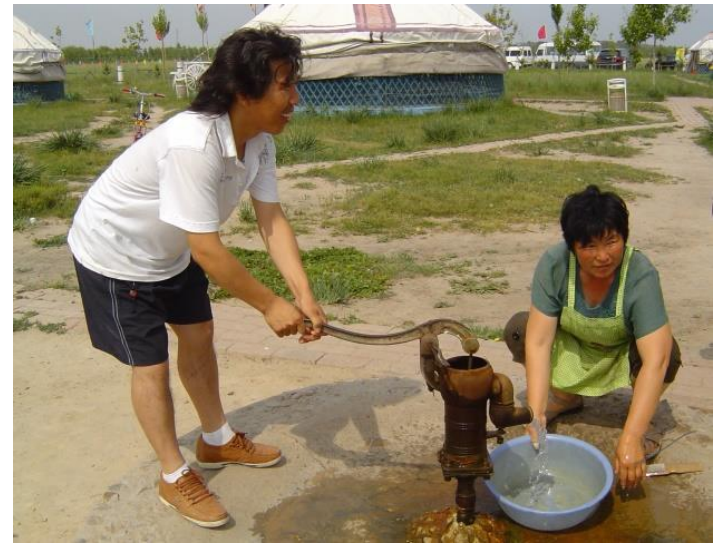

Fig. 5. A traditional Mongolian pump to extract water (author's photo)

Employment in the ethnographic facility is a source of additional income for the Mongols. Many of them produce and sell souvenirs, traditional hats and shoes, jewelry, toys, household utensils. Similar types of services are offered by the Mongolian population in the Zhalong Nature Reserve located in Qiqihar [6].

\section{Conclusion}

The study of the Mongols of China as representatives of the non-Han population and carriers of the national culture that preserves the traditional way of life and economic structure is of interest to historians, ethnographers, cultural scientists, sociologists, and representatives of other scientific areas. Among the most important ethnographic features of the Mongols of China are

- a steady increase in their numbers reduced only in the last 15-20 years after the implementation of birth control measures to the non-Han population of China;

- due to a decrease in the birth rate, the age structure changed (a decrease in the number of children and a gradual increase in the elderly people);

- the gender structure: equal shares of men and women in all age groups;
- main areas of Mongolian settlements are located in the north, north-east and north-west of China, with the largest share of people in the autonomous region of Inner Mongolia which is the first national territorial entity in China;

- the Chinese Mongols preserve ethnocultural values, the native language, customs, traditions, although the process of ethnic assimilation and diversification of the economy transformed the lifestyle of the Mongols;

- Ethno-tourism has become one of the popular areas for preserving the sociocultural environment and national identity.

\section{References}

1. I. V. Stavrov, Tendencies of demographic development of non-Han nationalities of Northeastern China (beginning of the 21st century). Herald of the Far Eastern Branch of the Russian Academy of Sciences, №4, 146-151, (2013)

2. Tabulation on the 2010 population census of the people's republic of china, China statistics press Retrieved from: http://www.stats.gov.cn/english/Statisticaldata/Censu sData/rkpc2010/indexch.htm (2010)

3. T. Bespyatov, China ethnic 2010 Retrieved from: http://pop-stat.mashke.org/china-ethnic-2010.htm (2010)

4. G.A. Ganshin, I.V. Ushakov, China: Economicgeographical essay. Moscow, Mys1, 2004.

5. N.A. Abramova, Regional dimension of the sociocultural space of modern China (Inner Mongolian Autonomous Region) Actual problems of the development of the PRC in the process of its regionalization and globalization. Chita: Transbaikalian State University, 13-20, 2014.

6. M.A. Voronina, Mongols of China: an ethnogeographical essay. Literature and culture of Siberia, the Far East and Eastern foreign countries. Problems of intercultural communication. Vladivostok: Far Eastern Federal University, 120-127, (2018) 